\title{
PERBANDINGAN DENSITAS PELET UO2 HASIL PELETISASI MENGGUNAKAN SERBUK DAN MIKROSPIR
}

\author{
Etty Mutiara, Meniek Rachmawati, Masrukan \\ Pusat Teknologi Bahan Bakar Nuklir-BATAN \\ Kawasan Puspiptek, Serpong, Tangerang Selatan, 15314 \\ e-mail: emutiara@batan.go.id
}

(Naskah diterima : 18-12-2015, Naskah direvisi: 08-01-2016, Naskah disetujui: 19-01-2016)

\begin{abstract}
ABSTRAK
PERBANDINGAN DENSITAS PELET UO ${ }_{2}$ HASIL PELETISASI MENGGUNAKAN SERBUK DAN MIKROSPIR $\mathbf{U O}_{2}$. Telah dilakukan pengembangan proses peletisasi menggunakan mikrospir $\mathrm{UO}_{2}$ sebagai pengganti serbuk $\cup_{2}$. Mikrospir bersifat speris, free flowing, porus dengan kekerasan tertentu (soft particle). Keunggulan penggunaan mikrospir pada proses peletisasi adalah tidak menimbulkan debu saat kompaksi dan lebih efektif dalam pengepakan sehingga tidak membutuhkan proses granulasi dan pelumas padat. Dihipotesakan bahwa penggunaan mikrospir $\mathrm{UO}_{2}$ dalam proses peletisasi akan memberikan densitas pelet sinter yang lebih tinggi dibandingkan dengan penggunaan serbuk $\mathrm{UO}_{2}$ pada parameter proses peletisasi yang sama. Mikrospir $\mathrm{UO}_{2}$ yang digunakan pada peletisasi ini berukuran $900 \mu \mathrm{m}$ dan crushing strength 2,0 N/partikel, sedangkan serbuk $\mathrm{UO}_{2}$ yang digunakan berukuran antara 150-850 $\mu \mathrm{m}$. Proses peletisasi mikrospir $\mathrm{UO}_{2}$ dan serbuk $\mathrm{UO}_{2}$ dilakukan dengan memvariasikan tekanan kompaksi antara $200 \mathrm{Mpa}$ hingga $500 \mathrm{MPa}$ dan disinter pada temperatur $1100^{\circ} \mathrm{C}$ selama 6 jam dalam suasana campuran gas hidrogen dan nitrogen. Karakterisasi dilakukan pada pelet mentah dan pelet sinter mikrospir $\mathrm{UO}_{2}$ dan serbuk $\mathrm{UO}_{2}$ yang meliputi pengukuran dimensi, penimbangan berat dan pengukuran densitas. Pada variasi tekanan kompaksi diperoleh pelet mentah dan pelet sinter mikrospir $\mathrm{UO}_{2}$ dengan densitas lebih tinggi dibandingkan hasil peletisasi serbuk $\mathrm{UO}_{2}$. Diperoleh hasil bahwa densitas pelet mentah baik hasil kompaksi serbuk $\mathrm{UO}_{2}$ maupun mikrospir $\mathrm{UO}_{2}$ meningkat dengan bertambahnya tekanan kompaksi. Densitas pelet mentah mikrospir $\mathrm{UO}_{2}$ berkisar antara 82,1 - 84,2 \%TD. Pada kondisi penyinteran yang sama, baik kompakan serbuk $\mathrm{UO}_{2}$ maupun kompakan mikrospir $\mathrm{UO}_{2}$ memperlihatkan densitas meningkat dengan semakin besar tekanan proses kompaksi. Dari penelitian ini belum diperoleh pelet sinter $\mathrm{UO}_{2}$ dengan densitas sesuai persyaratan reaktor pengguna sehingga diperlukan penelitian lanjutan terkait parameter proses peletisasi dan spesifikasi mikrospir $\mathrm{UO}_{2}$ yang efektif dalam memberikan pelet sinter $\mathrm{UO}_{2}$ dengan densitas sesuai persyaratan.
\end{abstract}

Kata kunci: peletisasi, $\mathrm{UO}_{2}$, mikrospir, serbuk, densitas. 


\section{ABSTRACT}

\section{A COMPARISON OF PELLETS DENSITIES IN PELLETIZATION PROCESS USING UO ${ }_{2}$} POWDER AND UO $\mathrm{O}_{2}$ MICROSPHERE. A pelletization process $\mathrm{UO}_{2}$ fuel has been developed using $\mathrm{UO}_{2}$ microsphere as a substitute of $\mathrm{UO}_{2}$ powder. Microspheres are spherical, free flowing and porous with certain hardness (soft particle). The benefit of using microsphere in pelletization process is dust free in compaction and more effective in packing so the granulation process and solid lubricants are not required. It is hypothesized that the use of $\mathrm{UO}_{2}$ microsphere in the pelletization process will provide higher sintered pellet density than $\mathrm{UO}_{2}$ powder at the same pelletization process parameters. $\mathrm{UO}_{2}$ microsphere size used in this pelletization was $900 \mu \mathrm{m}$ with crushing strength of $2.0 \mathrm{~N} /$ particles while the $\mathrm{UO}_{2}$ powder size between 150 and $850 \mu \mathrm{m}$. The pelletization processes of $\mathrm{UO}_{2}$ microsphere and $\mathrm{UO}_{2}$ powder were performed by varying the compacting pressure between $200 \mathrm{Mpa}$ up to 500MPa and sintered at temperatures of $1100^{\circ} \mathrm{C}$ for 6 hours in an atmosphere of hydrogen and nitrogen gas mixture. Characterizations performed on the green and sintered pellets of $\mathrm{UO}_{2}$ microsphere and $\mathrm{UO}_{2}$ powder were dimension measurements, weighing and densities measurements. The densities of green and sintered pellets of $\mathrm{UO}_{2}$ microsphere were higher than the green and sintered pellets densities of $\mathrm{UO}_{2}$ powder with corresponded compaction pressure variations. The results indicate that the density of the green pellets both compaction results $\mathrm{UO}_{2}$ powder and $\mathrm{UO}_{2}$ mikrospir increased with increasing compacting pressure. Mikrospir UO2 pellets density crude ranged from 82.1 to $84.2 \%$ TD. At the same sintering conditions, both Compaction UO2 powder and UO2 mikrospir Compaction shows the density increases with the greater pressure compacting process. The sintered pellets densties of $\mathrm{UO}_{2}$ obtained from this research were not appropriate with density requirements of PWR fuel. It is necessary to perform advanced research related to the effective pelletization process parameters and $\mathrm{UO}_{2}$ microsphere specifications in providing the appropriate sintered pellets densities.

Keywords: $\quad$ pelletization, $\mathrm{UO}_{2}$ microsphere, powder, density 


\section{PENDAHULUAN}

Pelet $\mathrm{UO}_{2}$ sebagai bahan bakar PLTN (Pembangkit Listrik Tenaga Nuklir) berpendingin air terus dikembangkan dalam rangka meningkatkan kinerjanya melalui peningkatan burn-up (derajat bakar) ${ }^{[1-3]}$. Peningkatan burn-up pelet $\mathrm{UO}_{2}$ akan menurunkan kebutuhan bahan bakar baru per energi yang dihasilkan sehingga pengoperasian PLTN lebih ekonomis ${ }^{[1,4]}$. Bahan bakar dengan burn-up tinggi mempunyai siklus bahan bakar dalam PLTN yang lebih panjang ${ }^{[1,3]}$. Hal ini menuntut peningkatan kehandalan bahan bakar $\mathrm{UO}_{2}$ agar PLTN dapat beroperasi dengan aman, selamat dan berkinerja tinggi[5].

Upaya yang dilakukan untuk memenuhi tuntutan di atas antara lain melalui fabrikasi pelet $\mathrm{UO}_{2}$ berbentuk annular[6] dan pemberian dopan ${ }^{[2,7-8]}$ untuk meningkatkan konduktivitas termal, fabrikasi pelet $\mathrm{UO}_{2}$ dengan jumlah pori tertutup dengan ukuran tertentu untuk meminimalkan pelepasan gas hasil fisi dan mengakomodasi swelling ${ }^{[9-11]}$. Segala upaya untuk peningkatan kehandalan pelet $\mathrm{UO}_{2}$ yang dilakukan tetapi kemampuan pencapaian densitas yang dipersyaratkan oleh reaktor pengguna wajib dipertahankan ${ }^{[2,12]}$.

Pelet $\mathrm{UO}_{2}$ untuk PLTN tipe PWR (Power Water Reactor) dengan densitas antara 94-96\% TD (true density) umumnya diperoleh melalui proses peletisasi konvensional yang terdiri dari proses kompaksi dingin serbuk $\mathrm{UO}_{2}$ dan proses penyinteran pelet $\mathrm{UO}_{2}$ mentah. Pada proses kompaksi serbuk $\mathrm{UO}_{2}$ dibutuhkan pengungkungan untuk melindungi pekerja dari radiotoxic dust hazard yang ditimbulkan ${ }^{[9-}$ 11,13]. Selain itu, ukuran serbuk $\cup_{2}$ dari jalur ADU (Amonium diuranat) diperoleh berukuran halus dan bersifat menggumpal (non free flowing) sehingga membutuhkan proses untuk membuat bentuk granular sebelum dilakukan kompaksi akhir ${ }^{[9,14]}$. Disamping itu, proses penyinteran pelet $\mathrm{UO}_{2}$ pun memerlukan pemanasan pada temperatur tinggi sekitar $1700{ }^{\circ} \mathrm{C}$ untuk memperoleh pelet $\mathrm{UO}_{2}$ dengan densitas tertentu sesuai persyaratan sebaagai bahan bakar.

Permasalahan yang terjadi pada proses peletisasi konvensional dapat diatasi/diperbaiki dengan menggunakan mikrospir $\mathrm{UO}_{2}$ sebagai pengganti serbuk $\mathrm{UO}_{2}$. Mikrospir umumnya berbentuk bulat dengan ukuran seragam, dan memiliki kekerasan permukaan partike[ ${ }^{[9,14]}$ tertentu, bersifat free flowing dan tidak menimbulkan debu saat dikompaksi[9,11,14-15]. Hal ini bisa menguntungkan karena dapat meniadakan atau tanpa proses granulasi dan kebutuhan pengungkungan untuk penanganan debu saat kompaksi.Selain itu, proses penyinteran pelet hasil kompaksi mikrospir dapat dilakuan pada temperatur lebih rendah dibanding proses penyinteran pelet hasil kompaksi serbuk $\mathrm{UO}_{2}{ }^{[16]}$.

Penggunaan mikrospir $\mathrm{UO}_{2}$ dapat meningkatkan derajat homogenitas mikro (micro-homogenity) pelet $\mathrm{UO}_{2}$ dengan memberikan komposisi relatif sama di setiap bagian pelet dan pori tertutup yang terdistribusi merata dalam pelet sinter ${ }^{[9,11,15,17]}$. Homogenitas ini sangat dibutuhkan terutama saat peletisasi menggunakan campuran oksida atau peletisasi serbuk $\mathrm{UO}_{2}$ dengan penambahan dopan. Pelet $\mathrm{UO}_{2}$ dengan komposisi yang seragam dan distribusi pori tertutup yang merata akan memberikan kemampuan pengungkungan gas hasil fisi yang merata di seluruh bagian pelet dan dapat mengakomodasi swelling pelet saat diiradiasi[9-10]. Kelebihan ini dapat dicapai dengan melakukan proses peletisasi menggunakan mikrospir yang porus ${ }^{[16]}$ dengan particle crushing strength yang rendah (soft particle) ${ }^{[9,11,14]}$. Pada peletisasi konvensional, derajat homogenitas mikro (micro-homogenity) pelet $\mathrm{UO}_{2}$ yang tinggi dapat dicapai melalui proses ball milling dengan durasi yang panjang sebelum 
serbuk campuran oksida dikompaksi ${ }^{[15]}$. Proses ball milling dan membuat bentuk granular akan memperpanjang alur proses kompaksi serbuk, sedangkan proses granulasi tidak diperlukan pada proses peletisasi menggunakan mikrospir ${ }^{[9,11]}$.

Mikrospir memiliki ukuran butir atau partikel yang relatif sama dan tidak mempunyai distribusi ukuran butir. Bila ditinjau dari sisi cara pengepakan partikel, maka partikel dengan distribusi ukuran tertentu (serbuk) akan memberikan kerapatan lebih tinggi dibandingkan dengan partikel yang berukuran seragam. Pada saat dikenai tekanan, partikel dengan ukuran lebih halus akan bergerak mengisi ruang kosong antar partikel dengan ukuran yang lebih besar sehingga pengepakan menjadi lebih rapat. Hal ini dapat dikompensasi dengan sifat mikrospir yang porus dan brittle akibat telah mengalami perlakuan panas atau kalsinasi. Dengan menggunakan tekanan kompaksi tertentu, mikrospir yang bersifat porus dan brittle serta berukuran seragam diduga akan terfragmentasi lebih lanjut dengan mekanisme tertentu sehingga berukuran lebih halus dengan distribusi tertentu yang menjadikan pengepakan mikrospir terfragmentasi lebih rapat. Dengan demikian proses kompaksi mikrospir yang porus dan memiliki crushing strength yang rendah (soft particles) akan memberikan densitas kompakan yang tinggi[9,11,14]. Mikrospir yang keras dan nonporus (densitas tinggi) kurang baik untuk kompaksi karena akan menurunkan interlok mekanik antar mikrospir sehingga densitas pelet mentah yang diperoleh lebih rendah[11,18]. Selain itu bentuk speris dari mikrospir akan memberikan flow ability yang tinggi[9,11,15], sehingga kompaksi mikrospir tidak membutuhkan lagi pelumas padat untuk mengatasi friksi antar partikel yang besar dalam rangka memperoleh densitas yang tinggi dan merata di sepanjang pelet. Dengan kata lain, mikrospir yang bulat dan porus dengan densitas rendah serta memiliki crushing strength yang rendah (soft particles) dan akan meningkatkan kompatibilitas serta kompresibilitas saat mikrospir dikenakan proses kompaksi.

Pada proses penyinteran, luas permukaan partikel yang besar merupakan driving force untuk laju difusi yang tinggi sehingga akan diperoleh pelet sinter dengan densitas yang tinggi. Serbuk yang memiliki mampu sinter yang baik adalah serbuk yang tersusun dari partikel yang agak lunak (fairly soft particles) dengan ukuran yang sangat halus dan mempunyai luas permukaan partikel yang realatif besar ${ }^{[19]}$. Mikrospir dimungkinkan untuk memiliki ukuran partikel lebih besar dibandingkan dengan serbuk, dapat bersifat porus dan rapuh atau brittle tergantung pada proses pembuatannya. Mikrospir yang porus, brittle dan memiliki crushing strength yang rendah (soft particles) dapat memberikan densitas pelet sinter yang ting i $^{[9,14]}$ karena luas permukaan partikel yang besar hasil fragmentasi pada saat kompaksi akan mendominasi dalam peningkatan laju difusi saat penyinteran. Hasil penelitian menyatakan bahwa pelet sinter hasil kompaksi mikrospir $\mathrm{UO}_{2}$ memiliki densitas antara 85 - 94\% TD yang diperoleh dengan proses penyinteran pada temperatur $1400{ }^{\circ} \mathrm{C}$ selama 6 jam ${ }^{[11]}$, sedangkan untuk densitas $96 \%$ TD diperoleh melalui proses penyinteran pada temperatur $1600^{\circ} \mathrm{C}$ selama 4 jam $^{[9]}$ atau $1350{ }^{\circ} \mathrm{C}$ selama 2 jam sampai 4 jam $^{[14]}$.

Penelitian ini merupakan pendekatan awal dalam mengelaborasi proses peletisasi menggunakan mikrospir $\mathrm{UO}_{2}$ jika dibandingkan dengan proses peletisasi serbuk $\mathrm{UO}_{2}$. Proses peletisasi menggunakan mikrospir $\mathrm{UO}_{2}$ dihipotesakan akan memberikan pelet mentah dan pelet sinter $\mathrm{UO}_{2}$ dengan densitas yang lebih tinggi dibandingkan menggunakan serbuk $\mathrm{UO}_{2}$. Untuk membuktikan hipotesa penelitian di atas, maka dilakukan kompaksi dengan variasi tekanan kompaksi baik terhadap mikrospir $\mathrm{UO}_{2}$ maupun serbuk $\mathrm{UO}_{2}$ dan disinter pada kondisi penyinteran yang konstan. Tekanan kompaksi divariasikan 
antara 200MPa hingga 500Mpa dan pelaksanaan proses penyinteran dilakukan pada temperatur $1100{ }^{\circ} \mathrm{C}$ selama 6 jam $^{[13]}$ dalam media gas campuran $\mathrm{N}_{2}$ dan $\mathrm{H}_{2}$. Densitas pelet mentah dan pelet sinter diukur untuk memperoleh informasi tentang peningkatan kerapatan atau densitas pelet hasil proses peletisasi menggunakan mikrospir $\mathrm{UO}_{2}$. Dari penelitian ini diharapkan diperoleh alternatif proses peletisasi dengan alur proses yang lebih pendek dan lebih aman yang akan menurunkan production cost dan menaikkan production rate dalam penyediaan pelet $\mathrm{UO}_{2}$ untuk memenuhi persyaratan reaktor pengguna.

\section{METODOLOGI}

Pabrikasi pelet $\mathrm{UO}_{2}$ dilakukan dengan menggunakan serbuk $\mathrm{UO}_{2}$ alam dan mikrospir $\mathrm{UO}_{2}$ alam. Serbuk $\mathrm{UO}_{2}$ yang digunakan mempunyai distribusi ukuran antara $75-850 \mu \mathrm{m}$. Mikrospir $\mathrm{UO}_{2}$ yang digunakan adalah mikrospir hasil perlakuan panas atau kalsinasi dengan ukuran ratarata sekitar $900 \mu \mathrm{m}$ dan crushing strength 2,0 N/partikel. Proses kompaksi dilakukan dengan variasi tekanan 200,300, 400 dan $500 \mathrm{MPa}$ menggunakan mesin kompaksi Komage (ME-02). Pelet mentah $\mathrm{UO}_{2}$ selanjutnya disinter pada temperatur $1100{ }^{\circ} \mathrm{C}$ selama 6 jam menggunakan tungku kalsinasi reduksi. Media penyinteran yang digunakan adalah campuran gas $\mathrm{N}_{2}$ dan gas $\mathrm{H}_{2}$. Selanjutnya dilakukan karakterisasi pelet sinter $\mathrm{UO}_{2}$ yang meliputi pengukuran dimensi, penimbangan berat dan perhitungan densitas. Data dimensi pelet diperoleh dengan cara mengukur tinggi dan diameter pelet menggunakan jangka sorong. Perhitungan densitas pelet diperoleh dengan cara membagi hasil pengukuran berat pelet menggunakan timbangan analitik dengan hasil perhitungan volume berdasarkan pengukuran dimensi.

\section{HASIL DAN PEMBAHASAN}

Densitas pelet mentah $\mathrm{UO}_{2}$ hasil pabrikasi serbuk $\mathrm{UO}_{2}$ dan mikrospir $\mathrm{UO}_{2}$ dengan variasi tekanan kompaksi ditunjukkan oleh Gambar 1, sedangkan densitas pelet sinter keduanya ditampilkan pada Gambar 2.

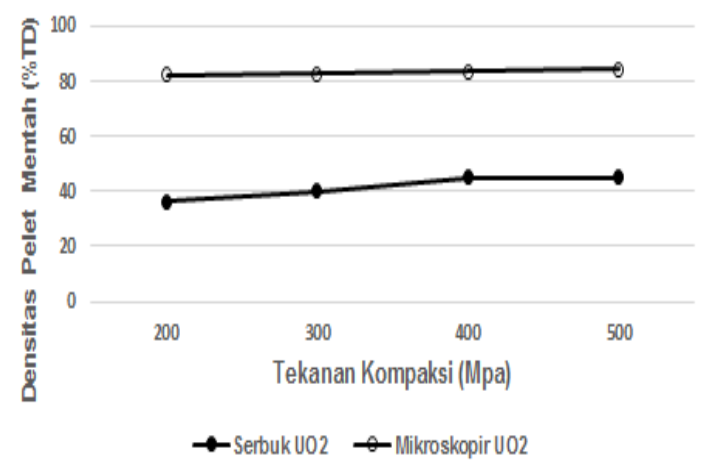

Gambar 1.Densitas pelet mentah serbuk $\mathrm{UO}_{2}$ dan pelet mentah mikrospir $\mathrm{UO}_{2}$ variasi tekanan kompaksi

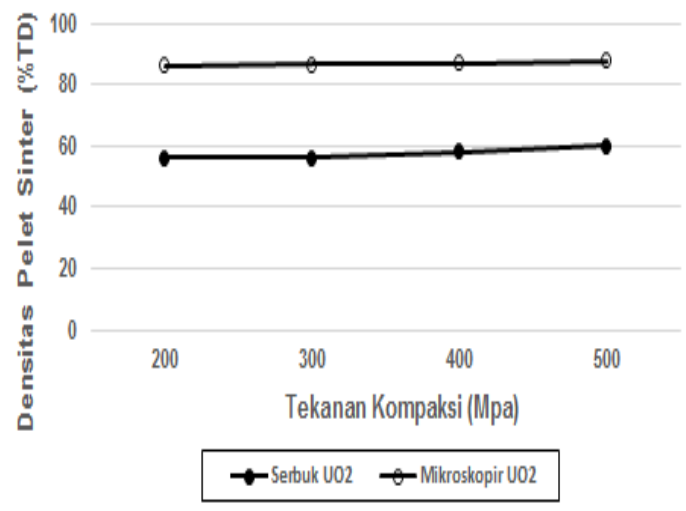

Gambar 2. Densitas pelet sinter serbuk $\mathrm{UO}_{2}$ dan pelet sinter mikrospir $\mathrm{UO}_{2}$ variasi tekanan kompaksi

Gambar 1 memperlihatkan bahwa densitas pelet mentah baik hasil kompaksi serbuk $\mathrm{UO}_{2}$ maupun mikrospir $\mathrm{UO}_{2}$ meningkat dengan bertambahnya tekanan kompaksi. Densitas pelet mentah mikrospir $\mathrm{UO}_{2}$ diperoleh berkisar antara 82,1 - 84,2\% TD. Densitas ini sangat tinggi bila dibandingkan dengan densitas pelet mentah hasil kompaksi serbuk $\mathrm{UO}_{2}$ pada tekanan kompaksi yang sama. Densitas tertinggi yang dapat dicapai pada kompaksi serbuk $\mathrm{UO}_{2}$ adalah antara $36-45 \%$ TD. Bentuk speris dari mikrospir $\mathrm{UO}_{2}$ akan memberikan 
flow ability yang tinggi. Hal ini berkontribusi dalam minimalisasi besar friksi antar partikel pada tahap awal proses kompaksi dan mempersingkat waktu yang dibutuhkan untuk proses pengepakan mikrospir dalam cetakan bila dibandingkan dengan serbuk $\mathrm{UO}_{2}$ yang cenderung menggumpal atau mengaglomerasi. Selain itu, diperkirakan telah terjadi fragmentasi lebih lanjut pada mikrospir $\mathrm{UO}_{2}$ pada saat kompaksi. Dengan tekanan kompaksi tertentu, mikrospir yang porus dan rapuh atau brittle akibat telah mengalami proses kalsinasi akan terfragmentasi sehingga berukuran lebih halus dengan distribusi tertentu yang menyeyebabkan pengepakan mikrospir terfragmentasi menjadi lebih rapat sehingga diperoleh densitas kompakan menjadi lebih tinggi[16]. Tingkat keporusan dan kerapuhan mikrospir sangat menentukan keberhasilan proses kompaksi mikrospir ${ }^{[9,11,14-15]}$. Peningkatan crushing strength pada mikrospir (mikrospir semakin tidak rapuh) menyebabkan mekanikal interlock antar partikel menjadi lebih rendah (tidak saling kunci) dan tidak terjadi fragmentasi sehingga menye-babkan densitas pelet mentah menjadi lebih rendah ${ }^{[18]}$. Pada penelitian ini dapat dikatakan bahwa mikrospir $\mathrm{UO}_{2}$ dengan karakteristik tertentu mempunyai kompresibilitas lebih tinggi dibanding serbuk $\mathrm{UO}_{2}$ pada setiap variasi tekanan kompaksi yang digunakan.

Gambar 2 memperlihatkan densitas pelet sinter kompakan serbuk $\mathrm{UO}_{2}$ dan kompakan mikrospir $\mathrm{UO}_{2}$ dengan variasi tekanan kompaksi. Pada kondisi penyinteran yang sama, baik kompakan serbuk $\mathrm{UO}_{2}$ maupun kompakan mikrospir $\mathrm{UO}_{2}$ memperlihatkan bahwa densitas meningkat dengan semakin besar tekanan proses kompaksi. Pada proses penyinteran, luas permukaan partikel yang besar merupakan driving force untuk laju difusi yang tinggi sehingga akan diperoleh pelet sinter dengan densitas yang tinggi. Serbuk yang memiliki mampu sinter yang baik adalah serbuk yang tersusun dari partikel yang agak lunak (fairly soft particles) dengan ukuran yang sangat halus yang mempunyai luas permukaan partikel yang besar ${ }^{[19]}$. Pada saat proses penyinteran diperkirakan ada beberapa hal yang berkemungkinan terjadi. Pertama adalah bila ditinjau dari kontribusi dari keras lunaknya partikel penyusun pelet terhadap densitas pelet sinter. Serbuk $\cup_{2}$ kemungkinan tersusun dari partikel yang lebih lunak dibandingkan partikel hasil fragmentasi mikrospir $\mathrm{UO}_{2}$ yang porus dan rapuh. Dengan demikian driving force proses difusi untuk densifikasi pada saat penyinteran kompakan serbuk $\mathrm{UO}_{2}$ lebih tinggi dari kompakan mikrospir. Hal ini dapat dilihat dari derajat densifikasi (shrinkage) pelet sinter mikrospir yang lebih rendah dibanding pelet sinter serbuk sebagaimana diperlihatkan pada Gambar 3.

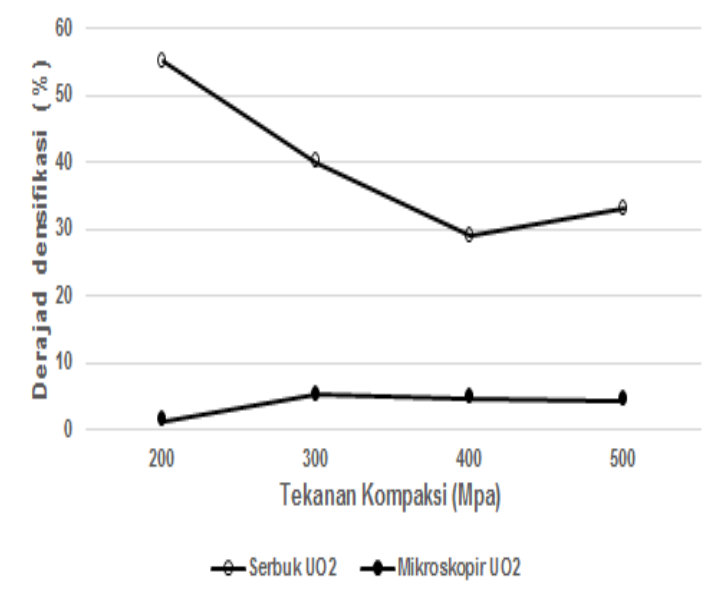

Gambar 3.Derajat densifikasi pelet sinter serbuk $\mathrm{UO}_{2}$ dan pelet sinter mikrospir $\mathrm{UO}_{2}$ variasi tekanan kompaksi

Namun, hal ini dikompensasi oleh luas permukaan yang besar karena tersusun dari partikel yang berukuran sangat halus hasil fragmentasi lebih lanjut pada mikrospir $\mathrm{UO}_{2}$ yang porus dan rapuh. Luas permukaan yang besar pada pelet mikrospir memberikan laju difusi yang tinggi sebagai driving force untuk perolehan densitas pelet sinter yang lebih tinggi dibandingkan pelet sinter serbuk. Selain itu terjadi juga kompetisi antara luas permukaan sebagai 
driving force laju difusi dengan densitas pelet mentah yang sudah tinggi sebagai penghalang difusi lebih lanjut dalam proses penyinteran kompakan mikrospir $\mathrm{UO}_{2}$. Hal ini menyebabkan derajat atau tingkat densifikasi pelet sinter mikrospir $\mathrm{UO}_{2}$ tidak tinggi.

Baik menggunakan serbuk $\mathrm{UO}_{2}$ maupun mikrospir $\mathrm{UO}_{2}$ dalam proses peletisasi, densitas pelet sinter $\mathrm{UO}_{2}$ yang diperoleh pada penelitian ini masih belum memenuhi persyaratan densitas bahan bakar untuk reaktor pengguna. Gambar 1 sampai dengan Gambar 3 memperlihatkan bahwa hasil kompetisi dari beberapa faktor terkait sifat serbuk dan sifat mikrosfir yang mempengaruhi proses kompaksi dan penyinteran pelet $\mathrm{UO}_{2}$ dalam pencapaian densitas yang tinggi. Kendati demikian, mikrosfir $\mathrm{UO}_{2}$ telah memperlihatkan trend yang menunjukkan beberapa keunggulan dibanding serbuk $\mathrm{UO}_{2}$ dalam proses peletisasi. Untuk itu, akan dilakukan pengembangan lebih lanjut terkait parameter proses peletisasi dan spesifikasi mikrospir $\mathrm{UO}_{2}$ yang efektif dalam memberikan pelet sinter $\mathrm{UO}_{2}$ dengan densitas sesuai persyaratan reaktor pengguna.

\section{SIMPULAN}

Proses kompaksi menggunakan mikrospir $\mathrm{UO}_{2}$ yang bersifat free flowing tidak membutuhkan tambahan pelumas padat dan mampu memberikan densitas yang lebih tinggi dibandingkan dengan penggunaan serbuk $\mathrm{UO}_{2}$. Diduga telah terjadi proses fragmentasi pada mikrospir $\mathrm{UO}_{2}$ selama proses kompaksi dengan mekanisme tertentu sehingga mikrospir $\mathrm{UO}_{2}$ yang terfragmentasi akan berukuran lebih halus dengan distribusi tertentu dan menjadikan pengepakan mikrospir terfragmentasi lebih rapat. Tekanan kompaksi sebesar 500MPa memberikan densitas pelet mentah tertinggi yaitu sebesar $84,2 \%$ TD. Hasil dari fragmentasi pada saat kompaksi mikrospir $\mathrm{UO}_{2}$ dapat meningkat-kan laju difusi proses penyinteran karena memberikan luas permukaan yang tinggi dan sistem pengepakan yang lebih efektif dibandingkan dengan penyinteran pelet dari serbuk $\mathrm{UO}_{2}$. Masih perlu dilakukan penelitian lebih lanjut terkait spesifikasi mikrospir $\mathrm{UO}_{2}$ dan parameter proses peletisasi yang efektif dalam memberikan pelet sinter $\mathrm{UO}_{2}$ dengan densitas yang lebih baik.

\section{UCAPAN TERIMA KASIH}

Penulis mengucapkan terima kasih kepada Ka.PTBBN - BATAN dan seluruh staf yang telah berkontribusi dalam pelaksanaan penelitian ini.

\section{DAFTAR PUSTAKA}

[1] Saji, E. et al (2009). Development of Advanced PWR Fuel and Core for High Reliability and Performance. Mitsubishi Heavy Industries Technical Review, Vol. 46, No. 4, 29 -34.

[2] Dooies, B.J. (2008). Enhancement of Uranium Dioxide Thermal and Mechanical Properties by Oxide Dopants. Master Thesis, University of Florida.

[3] Balakrishna, P. (2012). ThO2 and (U,Th)O2 Processing. A Review. Natural Science 4, 943 - 949.

[4] Spino, J. et al (2012). Bulk-Nanocrystalline Oxide Nuclear Fuels - An Innovative Material Option for Increasing Fission Gas Retention, Plasticity and Radiation Tolerance. Journal of Nuclear Material 422, 27 - 44.

[5] Zinkle, S.J. et al (2014). Accident Tolerant Fuels for LWRs: A Perspective. Journal of Nuclear Materials 448, $374-379$.

[6] Mozafari, M.A. et al (2013). Design of Annular Fuels for Typical VVER-1000 Core: Neutronic Investigation, Pitch Optimization and MDNBR Calculation. Annals of Nuclear Energy 60, 226 234. 
[7] Zhou, W. et al (2015). Fabrication Methods and Thermal Hydraulics Analysis of Enhanced Thermal Conductivity $\mathrm{UO}_{2}-\mathrm{BeO}$ Fuel in Light Water Reactor. Annals of Nuclear Energy, 81, $240-248$.

[8] Staicu, D. et al (2014). Effect of Burn-up On The Thermal Conductivity of Uranium-Gadolinium Dioxide up to $100 \mathrm{GWd} / \mathrm{tHM}$. Journal of Nuclear material 453, $259-269$.

[9] Kutty, P.S. et al (2013). Fabrication of Dense $\left(\mathrm{Th}_{0.96} \mathrm{U}_{0.04}\right)_{2}$ by Sol $\mathrm{Gel}$ Microsphere Pelletisation (SGMP) Route. BARC/2013/E/001, Bhabha Atomic Research Centre, Mumbai, India.

[10] Ganguly, C. et al (1991). Fabrication of High Density $\mathrm{UO}_{2}$ Fuel Pellets Involving Sol-Gel Microsphere Pelletisation and Low Temperature Sintering. Journal of Nuclear Material, 178, 179 - 183.

[11] Remy, E. et al (2012). Calcined Resin Microsphere Pelletization (CRMP): A Novel Process for Sintered Metallic Oxide Pellets. Journal of the European Ceramic Society, 32, $3199-3209$.

[12] Song K.W., Jeon K.L., Jang Y.K., Park J.H. and Koo Y.H. (2009), "Progress In Nuclear Fuel Technology In Korea", Nuclear Engineering And Technology, Vol.41 No.4 p.493-520.

[13] Meniek, R. et al (2013). Research on Sol-gel Microsphere Pelletization of $\mathrm{UO}_{2}$ for PHWR Fuel in Indonesia. IAEA Tecdoc CD 1751.
[14] Pai, R.V. et al (2008). Fabrication of Dense (Th,U) $\mathrm{O}_{2}$ Pellets Through Microspheres Impregnation Technique. Journal of Nuclear Material 381, 249 258.

[15] Kumar, N. et al (2006). Preparation of $(\mathrm{U}, \mathrm{Pu})_{2}$ Pellets Through Sol-Gel Microspheres Pelletization Technique. Journal of Nuclear Material 359, 69 79.

[16] Cologna, M. et al (2015). SubMicrometre Grained $\mathrm{UO}_{2}$ Pellets Consolidated from Sol Gel Beads Using Spark Plasma Sintering (SPS). Ceramics International, ARTICLE IN PRESS.

[17] Sokucu, A.S. et al (2014). Study on Preparation and First-Stage Sintering Kinetics of $\mathrm{ThO}_{2}-\mathrm{UO}_{2}$ Pellets Made by Sol-Gel Microsphere Technique. Acta Physica Polonica A, Vol. 127, No.4, $987-991$.

[18] Ferreira, R.A.N. et al (2006). A Model for The Behavior of Thorium Uranium Mixed Oxide Kernels in The Pelletizing Process. Journal of Nuclear Material $350,271-283$.

[19] Yulianto, T. et al (2013). Proses Pengompakan dan Penyinteran Pelet CERMET UO $\mathrm{U}_{2} \mathrm{Zr}$. Jurnal IImiah Daur Bahan Bakar Nuklir URANIA, Vo.19, No.1,39-46. ISSN No. 1907-2635, Akreditasi No.416/AU2/P2MI-LIP/04/2012 